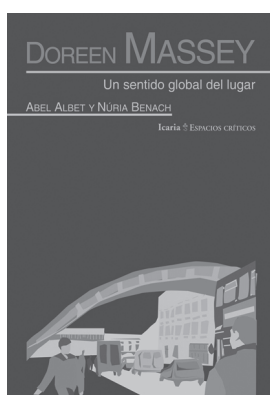

\title{
Abel Albet y Núria Benach. Doreen Massey. Un sentido global del lugar
}

\author{
Barcelona: Icaria, Colección Espacios Críticos, \\ 2012. 312 p.
}

\author{
José Ignacio Vigil ${ }^{1}$
}

La colección Icaria / Espacios Críticos, dirigida por Abel Albet y Núria Benach aparece como un espacio para traer al público académico hispanoparlante algunas de las más relevantes contribuciones de la geografía crítica reciente. En ese marco, el libro de la geógrafa Doreen Massey, o vale decir el libro que compila los argumentos más interesantes de la obra de Massey, aparece como una excelente muestra de la propuesta de la colección, que excede la mera traducción y recopilación de textos inéditos.

Titulado "Un sentido global del lugar", el libro se edita en un momento importante del pensamiento espacial crítico, más allá de que suele aparecer como un momento crucial también en la vida misma de la autora: su inminente retiro de la academia y una creciente revalorización de su profundísimo aporte a repensar la forma en que se comprende el espacio. Digo crucial porque cada vez más, al menos en algunos campos de la geografía, han empezado quizá con más fuerza que antes a visualizarse los tempranos aportes de Massey. Solo a modo de ejemplo, en el ámbito de las discusiones regionalistas pareciera haber un breve giro hacia la inclusión de algunos de sus legados en la reciente revisión conceptual que emprendiera la Unión Europea sobre la idea de una "Europa de las Regiones" (Farole et al., 2009)². En el con

1 Instituto de Investigación Estado, Territorio y Economía (IIETE), Universidad Nacional del Litoral (Argentina).E-mail: jvigil@fce.unl.edu.ar

2 Aunque, por otro lado, persisten aun de manera muy fuerte en algunas instituciones responsables de políticas regionalistas aquellas concepciones con las que quizá Massey no esté muy de acuerdo: ver por ejemplo el informe del Banco Mundial sobre texto latinoamericano, sirva también como ejemplo de la relevancia actual del aporte de Massey -entre muchos otros seguramenteque el ILPES/CEPAL (Instituto Latinoamericano y del Caribe de Planificación Económica y Social/ Comisión Económica para América Latina y el Caribe), un organismo central de pensamiento estratégico latinoamericano, ha invitado recientemente a Massey para debatir sobre políticas estratégicas y regionales en América Latina ${ }^{3}$. Quizá también pueda mencionarse la invitación a Massey del gobierno argentino, en el marco de transformaciones en la postconvertibilidad, para debatir sobre los procesos de desarrollo y sobre aquello -como veremos luego- de que los espacios están cargados de prácticas de poder, y de que entender esos elementos es fundamental en las implicancias de los procesos de transformación ${ }^{4}$. Incluso revistas académicas especializadas en problemas

\footnotetext{
las regiones (World Bank, 2009); y ver también las acaloradas respuestas críticas a dicha propuesta en (Peck \& Sheppard, 2010) y en la edición especial de Economic Geography: Issue 86 (4), 2010.

3 I Encuentro de Expertos Gubernamentales en Políticas de Desarrollo Territorial en América Latina y el Caribe: CEPAL de Santiago de Chile, 17-19/10/2012 (http://www.cepal.org/cgi-bin/getProd.asp?xml=/ ilpes/noticias/paginas/7/47817/P47817.xml\&xsl=/ ilpes/tpl/p18f.xsl\&base=/ilpes/tpl/top-bottom.xsl)

4 Ver la presentación de Massey en el panel "Nuevas prácticas democráticas en América del Sur" perteneciente al ciclo de filosofía y política titulado Debates y Combates que Ilevó adelante la Secretaría de Cultura de la Presidencia de la Nación Argentina durante los días 11 y 12 de octubre de 2012 en el pabellón de Cultura en Tecnópolis, Disponible en Internet: http://v2012.cultura.gob.ar/prensa/index. php $\% 3$ Finfo=noticia\&id $=1862 . \mathrm{html}$
} 
urbanos y regionales han dedicado recientemente números específicos a recibir trabajos que permitan visualizar el aporte de Massey a revertir problemas urbanos y regionales ${ }^{5}$. Quizá habrá muchos otros ejemplos más para indicar que se está (re)descubriendo a Massey o que algunas de sus ideas están teniendo ahora -y en América Latina- más fuerza que en otra época. Lo cierto es que, adaptando una de sus propias frases: ¡Massey (todavía) Importa! Y la edición de este libro con su obra contribuye de buena manera a ese camino de mostrar y poner en valor su aporte.

Déjeseme revisar el contenido del libro. Por un lado, la compilación es interesante porque avanza en la comprensión del ser humano mismo que dispara ideas y conceptos, que revisa y desintegra aspectos tan elementales y aceptados sin discusión como el espacio y la espacialidad para volver a reinterpretarlos y darles nuevos sentidos. Por su importancia, me gustaría brevemente describir este aspecto antes de avanzar sobre el resto de la obra. En su primera parte, el libro contiene un repaso de la trayectoria de vida de la autora. Allí se mencionan situaciones como la descripción de su niñez en un barrio de la working class de Manchester y su paso por la elitista universidad de Oxford, de gran impacto personal en Massey por el contraste con su infancia. Se indican aspectos de su participación en iniciativas y movimientos de izquierda o su intervención como asesora en las comisiones de la alcaldía de Londres (con Livingstone al frente, al que luego va a criticar por su persistencia con proyectos que ella creía no estaban acordes a un alcalde de "izquierda" (Massey, 2007), pasando por su seguramente "incómoda" vida durante el régimen quizá más neoliberal que haya existido (Thatcher). Se describen anécdotas sobre su rol en el asesoramiento al gobierno de Nicaragua, de México y de Venezuela; este último con una manifiesta adopción de algunos de sus postulados teóricos, transformados en iniciativas y principios políticos. Se menciona incluso su rol en la difusión de sus

\footnotetext{
5 Ver la reciente llamada de trabajos de la Revista Brasileira de Estudos Urbanos e Regionais, una publicación brasilera de la Associação de Pósgraduação e Pesquisa em Planejamento Urbano y Regional (ANPUR) de Brasil http://www.anpur.org.br
}

ideas escribiendo en colaboración con artistas para mejorar la comprensión del espacio (recomiendo por cierto la película Robinson in Space). Se detallan también elementos que tienen que ver son la manera de su escritura, tan limpia, clara, cargada de vivencias personales (su barrio, sus viajes con su hermana, etc.) y al mismo tiempo de gran altura teórica. Se narran aspectos de su comportamiento político-panfletario y su compromiso social y hasta militante (hay textos académicos de notoria implicancia política y muchos de sus colegas suelen hablar del lenguaje de Massey como $50 \%$ académico y $50 \%$ político). Se comenta incluso sobre su opción por trabajar en una universidad como la Open University, y hasta de su afección física, de su edad, de su retiro, y de su futuro inmediato. Toda la rica mención a estos elementos no es ni casual ni anecdótica para el libro y para entender la obra de Massey.

Por otro lado, en relación con la línea conceptual de Massey, el libro retrata muy bien su propuesta espacial. Hay varios aspectos y líneas de trabajo en su amplia proposición, pero me gustaría mencionar algunos en particular que creo son importantes y están bien recuperados en el libro, al tiempo que me gustaría colocarlos en línea con algunas de las orientaciones e implicancias que generaron. De más está decir que sus propuestas corren con la brillantez de haberse iniciado hace 30 años, cuando hablar de una nueva visión para entender el espacio y el lugar era quizá o-mejor dicho- seguramente, más original y audaz que ahora.

Primero, Massey ha sugerido tempranamente que los lugares, y por ejemplo sus problemas económicos, no necesariamente deben leerse como estrictamente "regionales", sino que pueden responder o descansar en procesos más amplios que el de un recorte territorial dado. Ha sugerido hasta el cansancio que debería poder pensarse que ciertos problemas pueden ser resultado de complejas combinaciones de sucesiones de roles dentro de una más amplia división del trabajo (por ejemplo, nacional e internacional) (Massey, 1979: 235). Eso que puede aparecer como obvio -como ella misma ha indicado- no parece haber sido sin embargo lo que estaba mayormente siendo considerando en los enfoques regionalistas. Lo que abundaba eran 
los trabajos que explicaban los problemas de las ciudades y las regiones como consecuencia exclusiva de la disposición espacial (ej. localización, conformación de atmósferas industriales, o bien, inexistencia de trabajadores con habilidades, o escasas políticas localistas, o falta de acciones innovadoras en los habitantes locales o de espíritu emprendedor, etc.). Así considerado, los lugares, localidades y regiones, podrían llegar a ser -en el mejor de los casos- artífices de su propio destino (si fueran exitosos), pero en su fase negativa, serían también culpables absolutos de su fracaso. Pero para Massey no parece ni lo uno ni lo otro: debía haber una diferencia entre decir que hay problemas de las regiones, y decir que hay problemas experimentados por las regiones.

Ese intento temprano de recontextualizar los lugares y los espacios regionales, quizá algo que parece simple, tiene a su vez consecuencias políticas muy importantes y significativas. Por ejemplo, en los términos de Massey puede implicar que las decisiones políticas sobre la manera de generar estrategias de desarrollo regional deban ir más allá de procesos de empoderamiento hacia los actores locales para que forjen su destino. Debería más bien implicar, por ejemplo y como ella misma lo advirtiera, que las regiones retrasadas sean, en parte producto también de que existen otras regiones que sí han logrado avanzar hacia niveles más altos de progreso y que ambas situaciones (éxitos y fracasos) están íntimamente relacionadas. Esto es clave en el pensamiento relacional del espacio propuesto por Massey: el desarrollo es desigual y los lugares están siempre vinculados o en relación con otros, y por tanto hay que estudiar ambos extremos de la situación simultáneamente. Massey analizó el caso de la división Norte-Sur en UK (Massey, 2001). En buena medida, las conclusiones para la acción política era que la relativa riqueza del sur tiene mucho que ver en la relativa pobreza del norte, y por tanto muchas de las acciones deben tomarse desde el sur (y no -solamente- desde el norte, en las regiones atrasadas, como normalmente pudiera haberse pensado) ${ }^{6}$. Desde

\footnotetext{
6 Ver al respecto los textos de Massey con sus colegas Amin y Thrift (Amin et al., 2003a, 2003b) Textos cuasi panfletarios -que Ilamativamente no aparecen
}

este quizá inicial disparador teórico, trabajado en mayor o menor medida en textos como "El problema regional", "Un sentido global del lugar", "Geometrías del poder", vendrán otros desprendimientos vinculados, por ejemplo, a la idea de la "geografía de la responsabilidad", como veremos luego.

Segundo, podría decirse también que Massey ha sugerido que los lugares, y en verdad cualquier entidad territorial, puede emerger de la conjunción de lo que 'previamente parece sin relación'; como entidades que pueden no ser internamente homogéneos o coherentes o con una identidad singular, o cerrada, con bordes fijos, o con una esencia preestablecida usualmente referida a lo parroquial, a lo íntimo. Por el contrario, propone su redefinición focalizando en la pluralidad y una multiplicidad que constituye el espacio, como una expresión de diferentes pero coexistentes trayectorias, como una entidad incompleta y en constante transformación. Una conceptualización compleja que Massey hace clara en la descripción de su barrio Kilburn high road al norte de Londres donde describe cómo la multiplicidad construye su lugar (Massey, 1993, 1994, 2005).

Déjeseme hacer aquí un breve paréntesis para rescatar un elemento central que permea todo el pensamiento de Massey, y que se vincula a la idea del espacio como una construcción social. Hay una imagen que quizá describe claramente esta expresión: por ejemplo -dice Massey- no podría explotarse carbón donde no haya un yacimiento, pero una mina de carbón simplemente no hace una "región económica". Y si entonces el espacio puede ser visto como una construcción social, es también una entidad en movimiento que expresa y contiene interacciones y conexiones, apertura, reconstrucción y cambio. Hay entonces una vinculación a la idea de 'proceso' (como opuesto a stasis) que permite dar relevancia al análisis de las 'trayectorias', entendidas como marcas dejadas por los actores e instituciones y que contribuyen a la conformación del lugar y el espacio.

en la compilación final que se hace de la obra de Massey- que plantean importantes implicancias políticas para revertir las relaciones norte/sur en Inglaterra. 
Cerramos el paréntesis y volvemos a la idea de la multiplicidad del lugar. Massey lo caracteriza con una nueva imagen: los lugares deben verse como "puntos de encuentro", como un mixture de influencias que se reúnen (Massey, 1999: 22). Entonces, aquello que puede a priori "aparecer sin relación", por ejemplo, flujos, conectividades, distancias, etc. no deben ser entendidos como contrapartes a la caracterización del lugar y el espacio. Por el contrario, el lugar y el espacio son la resultante del encuentro de esos elementos (Massey, 2005: 83). El argumento ha sido relevante para entender por ejemplo, que las identidades regionales pueden ser constituidas por interacción más que en términos de 'raíces comunes', evitando la idea de un 'nosotros' (lo local) vs. un 'ellos' (lo global, lo externo). Emerge entonces la idea de que los lugares son "únicos" pero no -necesaria o únicamente- por su "parroquialidad" sino porque se constituyen como puntos de encuentro de conexiones e intereses. Ello ha tenido a su vez una connotación metodológica y política importante. Por ejemplo, ha permitido generar proyectos alternativos a la conformación de localismos, o proyectos diferentes a los que tienden a mantener una resistencia local contra "Io externo", lo "lejano", lo "distinto". Precisamente -como dijimos- la conjunción de esos elementos es lo que define lo local: es ese precisamente el sentido global del lugar del que tanto habla Massey.

En ese contexto de espacios construidos por relaciones sociales plurales y distantes, algunos autores han trabajado la idea de la construcción del espacio fruto ya no del poder ejercido "territorialmente" (como reivindicaciones localistas) sino como fruto del ejercicio del "poder nodal", fruto de la conformación de redes y asociaciones ${ }^{7}$. Y más aún, bajo las mismas ideas de Massey sobre que ¡la geografía importa! Y en esta línea de la teorización sobre el poder y el espacio, se han retomado más recientemente las discusiones sobre las modalidades del ejercicio del poder, y de la variedad de mediaciones espaciales que tiene la construcción del espacio hecho de relaciones de actores ubicados en

\footnotetext{
7 Ver por ejemplo los trabajos de los colegas de Massey (Amin \& Thrift, 1995).
}

múltiples y cambiantes geografías, con intereses divergentes ${ }^{8}$.

Tercero, pensar globalmente los lugares ha dado paso también a teorizar en Massey sobre la relación espacio / tiempo, globalización y procesos de desarrollo ("Imaginar la globalización: las geometrías del poder del tiempo-espacio"). Su preocupación en buena medida ha sido cómo repensar la idea de progreso, o bien cómo evitar reducir las "diferencias espaciales" a "diferencias en desarrollo temporal". Esto es, cómo pensar el desarrollo de manera que no esté atado a transitar etapas que sean fruto de un proceso lineal, donde los lugares, regiones y países periféricos no son espacios autónomos y diferentes, sino solo un estadio más atrás en la etapa de progreso. Eso sería reducir el espacio al transcurso del tiempo. La preocupación de Massey es salir entonces de la mirada centro-europea que ha contado mayormente esta historia del desarrollo lineal basada en las representaciones construidas a partir de los sistemas de dominio y conocimiento. Comprender así el espacio no implica deshabitarlo de estructuras de poder y trayectorias condicionantes (esa es en todo caso -dice la autora- la mirada economicista neoliberal de libertad de movilidades siempre posibles), sino que invita a revisar las geometrías de poder que construyen el espacio (como fuera visto para el caso de las relaciones norte-sur en Inglaterra).

Complementando el punto anterior, el libro recopila también una idea trabajada por Massey sobre Geografía de la responsabilidad; esto es, el análisis de cómo y quién construye el (nuestro) espacio, pero también sobre el rol que la construcción de dicho espacio tiene hacia afuera, hacia otros lugares estrechamente vinculados: es casi una mirada introspectiva sobre cómo lo local influye en lo global, aunque cuidando de convertirlas en categorías separadas, puesto que, como hemos repetido aquí, en Massey lo local y lo global se unen indefectiblemente. En tiempos de transformaciones latinoamericanas su propuesta debería poder germinar en tierra

\footnotetext{
8 Ver por ejemplo los trabajos de un gran colaborador de Massey en la Open University (Allen, 2003, 2008, 2011).
} 
fértil, permitiendo repensar las oportunidades del espacio autónomo, rediseñando nuevas estrategias globales y alianzas interestatales en los países y regiones latinoamericanas. Ese es, quizá, el mensaje final hacia rediseñar las geometrías del poder que plantea Massey hacia muchos de los países latinoamericanos.

Finalizando la obra, los editores presentan una puesta en valor de la obra de Massey, una síntesis abreviada de su pensamiento y un muy útil viaje por las varias conceptualizaciones, aportes y críticas que la autora fue capaz de generar (y recibir!), académica y políticamente. Un cierre verdaderamente completo, como para volver a decir que ¡Massey importa!

\section{Referencias bibliográficas}

ALLEN, J. Lost Geographies of Power. Oxford: Blackwell Publishing, 2003.

ALLEN, J. Pragmatism and power, or the power to make a difference in a radically contingent world. Geoforum, 2008, Vol. 39, $N^{\circ} 4$, p. 1.613-1.624.

ALLEN, J. Topological twists: power's shifting geographies. Dialogues in Human Geography, 2011, $\mathrm{N}^{\circ} 1$. (In press).

AMIN, A.; MASSEY, D. \& THRIFT, N. Decentering the Nation: A Radical Approach to Regional Inequality. London: Catalyst, 2003a.

AMIN, A.; MASSEY, D. \& THRIFT, N. Regions, democracy and the geography of power. Soundings, 2003b, N²5, p. 57-70.

AMIN, A. \& THRIFT, N. Institutional issues for the European regions: from markets and plans to socioeconomics and powers of association. Economy and Society, 1995, № 24, p. 41-66.

FAROLE, T.; RODRÍGuEZ-POSE, A. \& STORPER M. Cohesion Policy in the European Union: Growth, Geography, Institutions. London: written in the context of the report An Agenda for a reformed Cohesion Policy for the European Commission, 2009.
MASSEY, D. In what sense a regional problem? Regional Studies, 1979, Vol. 13, N² p. 233-243.

MASSEY, D. Power-Geometry and a Progressive Sense of Place. Mapping the Futures: Local Cultures, Global Change. London and New York: Routledge, 1993, p. 59-69.

MASSEY, D. A global sense of place. In: MASSEY, D. (editor). Space, Place and Gender. Minneapolis: University of Minnesota Press, 1994.

MASSEY, D. Spaces of politics. In: Human Geography Today. London: Polity Press, 1999, p. 279-294.

MASSEY, D. Geography on the agenda. Progress in Human Geography, 2001, Vol. 25, $\mathrm{N}^{\circ} 1$, p. 5-17.

MASSEY, D. For Space. London: Sage, 2005.

Massey, D. World City. Cambridge: Polity Press, 2007.

PECK, J. \& SHEPPARD, E. Worlds Apart? Engaging with the World Development Report 2009: Reshaping Economic Geography. Economic Geography, 2010, Vol. 86, № 4, 331-340.

WORLD BANK. Reshaping Economic Geography. World Development Report. Washington D.C.: World Bank, 2009. 
